
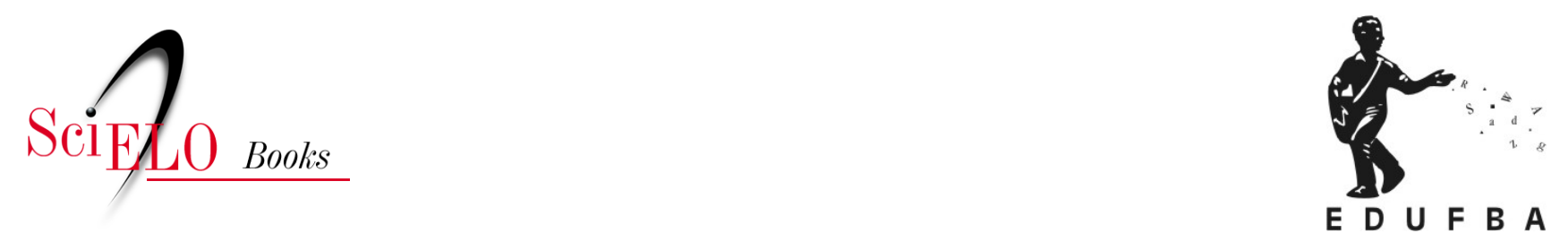

\title{
9 Tribo Gochnatieae (Benth. \& Hook. f.) Panero \& V.A. Funk
}

\author{
Nádia Roque \\ Gisela Sancho
}

ROQUE, N., and SANCHO, G. Tribo Gochnatieae (Benth. \& Hook. f.) Panero \& V.A. Funk. In: ROQUE, N. TELES, A.M., and NAKAJIMA, J.N., comp. A família Asteraceae no Brasil: classificação e diversidade [online]. Salvador: EDUFBA, 2017, pp. 77-80. ISBN: 978-85-232-1999-4.

https://doi.org/10.7476/9788523219994.0011.

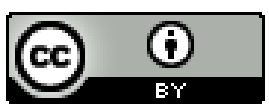

All the contents of this work, except where otherwise noted, is licensed under a Creative Commons Attribution 4.0 International license.

Todo o conteúdo deste trabalho, exceto quando houver ressalva, é publicado sob a licença Creative Commons Atribição $\underline{4.0}$. 


\section{TRIBO GOCHNATIEAE (BENTH. \& HOOK. F.) PANERO \& V.A. FUNK}

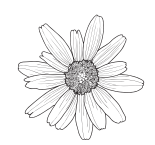

Nádia Roque

Gisela Sancho

Gochnatieae (subfamília Gochnatioideae) foi reconhecida como uma tribo dentre as linhagens basais de Asteraceae (PANERO; FUNK, 2002). Anteriormente, os gêneros estavam inseridos na subtribo Gochnatiinae, da tribo Mutisieae (CABRERA, 1977), mas a maioria das espécies foi excluída quando a circunscrição de Mutisieae revelou-se não monofilética (PANERO; FUNK, 2002, 2008). O tratamento taxonômico proposto por Panero e Funk (2002) reconheceu 4 gêneros em Gochnatieae: Cnicothamnus Griseb., Cyclolepis Gilles ex D. Don, Gochnatia Kunth, Richterago Kuntze e possivelmente Chucoa Cabrera.

Contudo, estudos moleculares recentes (FUNK et al., 2014) revelaram 8 clados monofiléticos em Gochnatieae, representados pelos gêneros Cnicothamnus (2 spp.), Richterago (16 spp.) (ROQUE; PIRANI, 2001, 2014), Pentaphorus D. Don (2 spp.) (Hind 2007), Anastraphia D. Don (33 spp.) (VENTOSA; HERRERA, 2011), Moquiniastrum (Cabrera) G. Sancho (21 spp.) (SANCHO; FUNK; ROQUE et al., 2013), Gochnatia Kunth (cerca de 8 spp.), Cyclolepis (1 sp.) e um gênero novo que inclui 7 espécies norte americanas. Dessa forma, a tribo totaliza cerca de 90 espécies, com distribuição restrita ao continente americano, desde o México (e áreas subjacente dos Estados Unidos), Caribe e América do Sul. 


\section{Descrição}

Ervas, subarbustos, arbustos ou árvores, monoicas, ginodioicas, ginomonoicas. Folhas simples, alternas, lâmina foliar discolor ou concolor, margem inteira, serreada, espinosa-denteada, denteada a denticulada, tomentosa, glabrescente ou glabra, tricomas glandulares sésseis, pecioladas a subsésses. Capitulescência racemiforme, espiciforme, corimbiforme, paniculiforme, glomeruliforme ou capítulo solitário e terminal, cilíndrico ou campanulado; receptáculo epaleáceo, plano a convexo. Capítulos discoides (Figuras 5F,G,I) ou radiados (Figura 5H), homógamos ou heterógamos, brácteas involucrais (2)3-15 séries, imbricadas, graduadas. Flores 3-300, tubo da corola glabro, pubescente ou com tricomas glandulares; flores do raio (quando presentes) com corola bilabiada $(3+1,3+2)$, pseudobilabiada $(4+1)$ ou sub-bilabiada (irregularmente lobada em Moquiniastrum), bissexuais (Cnicothamnus) ou pistiladas (Richterago, Moquiniastrum), alva, rósea ou laranja a laranja avermelhada, estaminódios 4-5 livres, hialinos (nas plantas ginodioicas, as flores da planta feminina não apresentam anteras); flores do disco bissexuais ou bissexuais e pistiladas ou todas pistiladas (Moquiniastrum, Cyclopepis), corola actinomorfa, com 5 lobos profundamente divididos, amarelo-alaranjada, amarela, creme-esverdeada, branca ou rósea, lobos eretos ou revolutos; estame com apêndice do conectivo da antera acuminado a apiculado, base da antera caudada, lisa a laciniada; estilete curtamente bilobado, glabro, ápice arredondado a obtuso (Figura 4G). Cipselas cilíndricas, costadas, vilosas, seríceas, tricomas glandulares bisseriados com vesículas em Anastraphia; pápus estramíneo, simples, cerdoso-escabroso, algumas vezes plumoso no ápice, raro paleáceo (Cnicothamnus), 1-3-seriado, 20 a 90 elementos, iguais ou desiguais no comprimento, livres a conados em um anel carnoso.

No Brasil, Gochnatieae está representada por três gêneros: Moquiniastrum, com 19 espécies, das quais 12 são endêmicas, e com distribuição extra-amazônica (Figuras 5F-G); Richterago, com 16 espécies endêmicas do Brasil e restrito a áreas abertas do domínio cerrado no leste do Brasil (Figuras 5H-I) e Gochnatia rotundifolia (Less.) Cabrera, uma espécie com registro para o cerrado no estado de São Paulo e que não tem sido coletada desde 1965. 


\section{Chave de identificação para os gêneros de Gochnatieae no Brasil}

1. Ervas em roseta ou subarbustos escaposos; flores alvas ou lilás, pápus unisseriado (Figura 4I) Richterago 1'. Árvores, arbustos, raramente subarbustos (M. cordatum); flores creme, pápus 2-3-seriado (Figura $4 \mathrm{H}$ ).

2. Plantas polígamo-dioicas ou ginodioicas; lâmina foliar com venação pinada; capítulos formando uma capitulescência (Figura 5G); invólucro 0,6$1 \times 0,4-0,7 \mathrm{~cm}$; flores 6-25, pápus cerdoso Moquiniastrum 2'. Plantas monoicas; lâmina foliar com venação trinervada; capítulos solitários no ápice dos ramos; invólucro $2,5 \times 2,5-3 \mathrm{~cm}$; flores mais 50 , pápus paleáceo na base e ápice plumoso

Gochnatia

\section{Literatura recomendada}

CABRERA, A. L. Mutisieae: systematic review. In: HEYWOOD, V. H.; HARBORNE, J. B.; TURNER, B. L. (Ed.). The Biology and Chemistry of the Compositae. London: Academic Press, 1977. v. 2. p. 1039-1066.

CABRERA, A. L. Revision del Genero Gochnatia. Revista Museo de La Plata, la Plata, v. 66, n. 12, p. 1-160, 1971.

FUNK, V. A. et al. A phylogeny of the Gochnatieae: understanding a critically placed tribe in the Compositae. Taxon, Utrecht, v. 63, n. 4, p. 859-888, 2014.

HIND, D. J. N. Tribe Mutisieae. In: K. KUBITZKI, K.; JEFFREY, C. (Ed.). The Families and Genera of Vascular Plant: v. VIII: Flowering Plants Eudicots: Asterales. Berlin: Springer-Verlag, 2007. p. 90-123.

PANERO, J. L.; FUNK, V. A. Toward a phylogenetic subfamilial classification for the Compositae (Asteraceae). Proceedings of the Biological Society of Washington, Washington, v. 115, n. 4, p. 909-922, 2002. 
PANERO, J. L.; FUNK, V. A. The value of sampling anomalous taxa in phylogenetic studies: major clades of the Compositae revealed. Molecular Phylogenetics and Evolution, Orlando, v. 47, n. 2, p. 757-782, 2008.

ROQUE, N.; PIRANI, J. R. Reinstatement of the name Richterago Kuntze and recircumscription of the genus to include species formerly treated as Actinoseris (Endl.) Cabrera (Compositae, Mutisieae). Taxon, Utrecht, v. 50, n. 4, p. 1155-1160, 2001.

ROQUE, N.; PIRANI, J. R. Taxonomic revision of Richterago Kuntze (Asteraceae, Gochnatieae). Systematic Botany, Kent, v. 39, n. 3, p. 997-1026, 2014.

SANCHO, G.; FREIRE, S. E. Gochnatieae (Gochnatioideae) and Hyalideae (Wunderlichioideae p.p.). In: FUNK, V. A. et al. (Ed.). Systematics, Evolution and Biogeography of Compositae. Vienna: IAPT, 2009. p. 249-265.

SANCHO, G.; FUNK, V. A.; ROQUE, N. Moquiniastrum (Gochnatieae, Asteraceae): a result of the paraphyletic Gochnatia. Phytotaxa, [S.1.], v. 147, n. 1, p. 26-34, 2013.

VENTOSA-RODRIGUEZ, I.; HERRERA OLIVER, P. P. Restoration of the name Anastraphia to define the species in the section Anastraphioides of Gochnatia (Gochnatioideae, Asteraceae). Compositae Newsletter, [S.1.], v. 49, p. 23-37, 2011. 